\title{
Solving Rate of Change Tasks with a Graphing Calculator: a Case Study on Instrumental Genesis
}

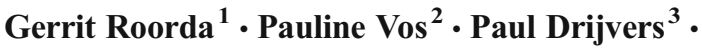 \\ Martin Goedhart ${ }^{4}$
}

Published online: 25 August 2016

(C) The Author(s) 2016. This article is published with open access at Springerlink.com

\begin{abstract}
In an increasing number of mathematics classes throughout the world, technology is being used for the teaching and learning of mathematics. But knowledge is limited about the long-term development of students' mathematical thinking when learning mathematics with the use of technology. This article reports on the development of a student and the role of the graphing calculator (GC) in his learning about derivatives and instantaneous rate of change. This case is compelling, because the student is an intensive user of the GC and develops flexible problem-solving techniques - techniques which differ from those of his peers and from what he was taught in mathematics class. We used the framework of instrumental genesis to investigate how this student's mathematical thinking was affected by the use of the GC. Over a 2-year period, we administered four task-based interviews involving problems on instantaneous rate of change situated in contexts. We found that the use of the GC may facilitate a learning process in which instrumentation schemes involving symbolical representations develop separately from those for the graphical and numerical use of the GC.
\end{abstract}

Keywords Graphing calculator - Instrumentation schemes - Derivative $\cdot$ Rate of change Long-term development · Instrumental genesis

Gerrit Roorda

g.roorda@rug.nl

1 Faculty of Behavioural and Social Sciences, Department of Teacher Education, University of Groningen, Grote Kruisstraat 2/1, 9712 TS Groningen, The Netherlands

2 Department of Mathematics, University of Agder, Gimlemoen 25, 4604 Kristiansand, Norway

3 Freudenthal Institute, Utrecht University, Princetonplein 5, 3584 CC Utrecht, The Netherlands

4 Faculty of Mathematics and Natural Sciences, University of Groningen, Nijenborgh 9, 9747 AG Groningen, The Netherlands 
Handheld technology is used in mathematics education in many ways. In an increasing number of mathematics classes throughout the world, students and teachers use calculators, laptops, tablets and smart phones for the learning and teaching of mathematics (e.g. An et al. 2014; Dunn et al. 2013). Meta-studies on the use of handheld technology in mathematics education showed a positive effect on mathematics achievement. For example, Cheung and Slavin (2013) reviewed 74 studies and conclude that educational technology applications produce a positive and significant effect on mathematics achievement, but with a small effect size.

A specific kind of handheld technology in mathematics classes is the graphing calculator (GC). Ellington (2003) carried out a meta-study, in which 54 studies on the effects of (graphing) calculators were analyzed. One of her conclusions was that, when calculators are included in assessment and instruction, students displayed improvement in intellectual means necessary for understanding mathematical concepts, such as the ability to make meaningful connections between functions and their graphs. Also, Burrill et al. (2002) and Delos Santos (2006) reported on evidence that the use of the GC improves the ability to link symbolical, graphical and numerical representations - in particular for the understanding of functions and algebraic expressions.

After the introduction of the GC in education, researchers zoomed in on the effects of its use on mathematical thinking of individual students. Trouche and Drijvers (2010) offered examples of changes in mathematical knowledge that are affected by the use of the GC, such as how the meaning of an equation can become more graphical to some students or how students' ideas about the graphical representation of a function can be hindered by inappropriate GC-window settings and pixel effects. Another effect of the use of the GC is the adoption by some students of a trial-and-error, button-pressing strategy to solve problems (Berry and Graham 2005). These examples show that development of students' mathematical knowledge is affected by opportunities and constraints of the technology.

So, on the one hand, there is evidence that using the graphing utilities of the GC can promote students to develop strong relationships between symbolical and graphical forms of functions and derivatives. On the other, the following questions stated by Burrill et al. (2002) are still relevant: 'What is the effect of handheld technology on students' ways of mathematical thinking?' and 'What are changes, if any, over time in the ways that students make use of the calculator?' (p. 46). They suggest that case studies of students while solving problems would be needed to answer such questions.

Inspired by these questions, we were interested in how a student's use of the GC and his or her way of mathematical thinking can develop over time. In this article, we report on a longitudinal case study undertaken in the Netherlands, in which we monitored the learning process of the concept of derivative (Roorda et al. 2015). From a sample of ten students, we identified one, Andy, who was an intensive TI-83 Plus user. We found this case compelling and important, because it illustrates the phenomenon of how a student's understanding of derivative can develop when it is affected by an intense use of the GC. We think that this case is not unique and that many teachers will recognize this type of student, who is attracted to using the GC. As such, this in-depth study of Andy's mathematical development aims to contribute to a better understanding of what can be some effects of the access to technology on possible developments in students' mathematical thinking. 


\section{Theoretical Background}

We first summarize outcomes of research on the learning of derivatives and effects of technology on the learning processes in calculus. Second, we describe the instrumental approach that is used as theoretical framework for our study.

\section{Understanding the Concept of Derivative}

The concept of derivative is complex in many ways. The mathematician Thurston (1995) states that there are different views on the concept, such as infinitesimal, symbolic, geometric, microscopic or rate. According to him, this is not a list of logical definitions, but rather a list of different ways to think about derivatives. The complexity of the concept is the cause for the complexity of researching students' understanding of the concept (e.g. Zandieh 2000). Building on this work, Roorda et al. (2007) described different aspects of the concept in a framework by distinguishing three representations and four layers (see Table 1).

The three representations are symbolic, graphical and numerical, as shown in the three columns. All three are typically available in a GC, in which a function can be inserted symbolically and then displayed in a table or as a graph by pressing some buttons. The four layers are the subsequent steps to go from a function to its derivative: by taking a difference quotient, then taking its limit to reach a differential quotient and then by generalizing across all $x$-values of the domain to reach the derivative function. Within Table 1, one can make many transitions: for example, the symbolic difference quotient can be represented graphically as the average slope. Vertical relations in Table 1 can be seen as process-object pairs (Zandieh 2000): for example, the relations between layers 2 and 3 represent the limiting process. The limit of the difference quotient $\frac{\Delta y}{\Delta x}$, when $\Delta x$ approaches to 0 , results in the object 'differential quotient' $\frac{\mathrm{d} y}{\mathrm{~d}}$.

Difficulties that students experience while studying the derivative may often be analyzed as missing, wrong or weak links in the derivative framework given in Table 1. Some studies (e.g. Kendal and Stacey 2003; Orton 1983; Zandieh 1997) showed instances of students who can carry out differentiation rules, but have difficulty relating the symbolic outcomes at layer 4 to graphs or tables. Kendal and Stacey concluded that many students had problems linking the numerical to the graphical and symbolic representations of layer 2 and 3. Park (2013) claimed that some students mix up the rate of change at a single point in layer 3 with the derivative at variable points in layer 4. Other studies reported on students' difficulties in understanding the limiting process from layer 2 to layer 3 (e.g. Hähkiöniemi 2006).

Table 1 Representations and layers of the derivative concept

\begin{tabular}{|c|c|c|c|}
\hline & Symbolic & Graphical & Numerical \\
\hline Layer 1 & function & graph of function & table \\
\hline Layer 2 & $\frac{\Delta y}{\Delta x}$ difference quotient & average slope (of secant line) & average rate of change (over an interval) \\
\hline Layer 3 & $\frac{\mathrm{d} y}{\mathrm{~d} x}$ differential quotient & slope of tangent line & instantaneous rate of change \\
\hline Layer 4 & derivative function & graph of derivative function & table with rates of change \\
\hline
\end{tabular}


Roorda et al. (2015) described that student ability to make transitions between representations and layers was an indicator of their conceptual understanding of the derivative. However, they added that for conceptual understanding, a student also needs to be able to explain relationships (across representations or layers), use appropriate language and recognize that different problems can be solved through similar procedures. Thus, the framework of Table 1 assists in analyzing tasks pertaining the derivative, but it does not capture exhaustively all aspects of students' conceptual understanding of the derivative.

As for instructional approaches to strengthen relationships within the concept of derivative, some researchers have focused on the use of graphing utilities of calculators. Delos Santos (2006), Heid (1997), and Leng (2011) showed how students can be supported by using the GC in demonstrating a multi-representational way of thinking with an appropriate use of a calculator's graphical, numerical and symbolic representations.

When looking at Table 1, some relationships among cells are easily made with the use of a GC. For example, one can introduce the rate function $\mathrm{Y} 2=(\mathrm{Y} 1(\mathrm{X}+0.001)-\mathrm{Y} 1(\mathrm{X})) / 0.001$ as an approximation of the derivative function. With this function, a transition between the graph of the original function (graphical layer 1) and the graph of the approximated derivative function (graphical layer 4) can be made, because both graphs can be seen simultaneously in a single window (Doerr and Zangor 2000), which may lead to an understanding of the rate of change as a function itself. Newer versions of the GC offer additional opportunities to calculate an approximation of instantaneous rate of change at one point. The GC used by the student in this article has an option, which we will denote by calc-d $y / \mathrm{d} x$, which approximates the steepness of the graph at one point. This is an immediate transition from layer 1 to layer 3 .

So, there are indications that using graphing utilities can assist students in developing relationships between symbolical and graphical forms of functions and their derivatives. However, Drijvers and Doorman (1996) observed that an intertwining of algebraic and graphical methods does not occur without struggle: students tended to regard the various methods as separate and they often choose a single method rather than linking the representations.

\section{Instrumental Genesis}

To study the interplay between the use of the GC and students' mathematical thinking, we use a theoretical framework known as the instrumental approach (e.g. Artigue 2002; Drijvers et al. 2013; Guin and Trouche 1998; Trouche 2004). In this account, artefacts are distinguished from instruments. An artefact is an object, which can be a physical object, but also a formula or a graph; central is that the artefact is used to carry out a given task. The term instrument refers to a psychological construct, which consists of a psychological component together with an artefact (Trouche 2004).

We call the psychological component of an instrument an instrumentation scheme, in which technical and conceptual elements are intertwined and co-develop. The instrumentation scheme integrates conceptual and technical knowledge of the use of the artefact. In the term 'instrumentation scheme', the word scheme is used in the sense of Vergnaud (2009), namely as the invariant organization of 
activity for a certain situation. These schemes contain operational invariants, which is the - often implicit - knowledge that is believed to be true and guides the use of the artefact. According to Vergnaud, schemes organize individual gestures and actions in the physical world, as well as interaction with other individuals.

The process of a person learning to use an instrument for a specific task while at the same time developing knowledge, in other words the process of constructing a scheme, is called instrumental genesis (Artigue 2002). It works in two directions: instrumentalization is directed towards the artefact, and includes eventually (re-)shaping, whereas instrumentation refers to the constraints and opportunities of the artefact shaping the user's thinking. The latter is the more important idea for the purpose of this study.

An important aspect of the instrumental approach is the duality scheme-technique. Following Drijvers et al. (2013), techniques are "the observable part of the students' work on solving a given type of tasks (i.e. a set of organized gestures)" and schemes are "the cognitive foundations of these techniques that are not directly observable, but can be inferred from the regularities and patterns in students' activities" (p. 27). In several studies, instrumentation schemes with their constituent technical and conceptual elements have been described (e.g. Drijvers and Barzel 2012). Drijvers et al. (2013) described two schemes of one student (Maria), namely a substitution scheme and a scheme on equation solving.

However, instrumentation schemes for working with derivatives have not been described before. A GC offers many possibilities for work on or with the derivative, because it is a device that integrates different artefacts (Drijvers et al. 2013; McCulloch 2011). A student who is working on a task can use several artefacts, each one being part of the instrument. Consequently, different instrumentation schemes can be distinguished.

In this article we distinguish techniques and schemes. Techniques are observable instances of mathematical activity to solve certain types of tasks, with or without a tool. For example, for calculating $f^{\prime}(4)$, there are different techniques: (1) one can calculate the derivative function $f^{\prime}(x)$ and fill in $x=4$ or (2) one can calculate $f(4+h)$ and $f(4)$, take the difference, divide by $h$, and take the limit for $h$ approaching to 0 . For each technique a different instrumentation scheme exists.

At the outset, we posed the question about possible effects of the GC on the development of a student's understanding of the concept of derivative. In terms of the instrumental approach, the research question addressed in this article is: Which instrumentation schemes can develop while using the GC in learning about the derivative? We not only describe the development of a repertoire of schemes, but also study changing preferences within this repertoire over time.

\section{Methods}

We used a case study approach, which can contribute to a better understanding of complex social phenomena (Yin 2014). The case study focuses on Andy, a Dutch student in the pre-university science and technology track, which means that he takes science and mathematics courses at an advanced level. We selected Andy because he is an example of students whose mathematical thinking is affected by 
intensive GC use. He was one of ten students in a longitudinal study, about which we reported earlier (Roorda et al. 2015), albeit without zooming in on Andy's GC use.

We followed these students over a period of two years, gaining insight into their long-term development. During that period, we administered four task-based interviews with problems on instantaneous rate of change and opted for a detailed description and analysis of their work. While other students increasingly used symbolic differentiation rules to calculate instantaneous rate of change, Andy preferred to use graphical and numerical techniques using his GC. The case of Andy gives insight into possible processes by which knowledge of the GC and of mathematics can develop in interaction.

Andy's mathematics teachers classified him as an 'average student', who worked quietly in their lessons, rarely asking questions. One of the mathematics teachers reported that he often made calculation errors in symbolic manipulation. Andy himself said that he preferred physics over mathematics: his physics teacher classified him as a 'good student'.

\section{The Tasks and the Task-Based Interviews}

Central to this study are four task-based interviews, labelled TBI-1, TBI-2, TBI-3 and TBI-4, which were administered at half-yearly intervals as the students progressed from grade 10 to grade 12. Task-based interviews allow a focus on students' thinking processes (Goldin 2000), opening a window onto students' knowledge, problemsolving behaviour and reasoning (Koichu and Harel 2007). The tasks were designed to provide in-depth information about students' mathematical thinking while using the concept of derivative, involving different representations (graphs, symbols, tables). To prevent the interviewees being directly cued to the symbolic nature or representation of the concept we avoided the explicit use of the mathematical terms derivative and differentiation, and symbols such as $\frac{\mathrm{d} y}{\mathrm{~d} x}$.

All the tasks made use of situated contexts, in which the variables had a concrete meaning, such as time, volume, distance or price, while the derivative had the meaning of the rate of change of certain of these variables (e.g. velocity, marginal costs). The interview protocol prescribed that a student, having completed a task, was first asked if he or she knew other approaches to solve the task, and next, if he knew an approach to check the answer. In this way, we could observe a range of techniques and see how various instrumentation schemes were developing.

In this article, we focus on three tasks: The Barrel task, the Monopoly task and the Costs task (see Fig. 1). We selected these tasks because they offer the interviewee opportunities to use numerical, graphical and symbolic representations to solve the tasks. The Barrel-a task was used in all four interviews. The Barrel-b task and the Monopoly task were used in TBI-1, TBI-2, and TBI-4. The Costs task was only used in TBI-3.

The focus of the analysis is on one aspect of these three tasks, namely, how Andy calculated instantaneous rate of change. Because the Barrel and Monopoly task 
The Barrel task (used in TBI-1, -2, -3, -4)

A barrel contains a liquid, which runs out through a hole in the bottom. The volume of the liquid in the barrel $\left(V\right.$ in $\left.\mathrm{m}^{3}\right)$ decreases over time ( $t$ in minutes). The volume of the liquid is expressed by the formula $V=10\left(2-\frac{1}{60} t\right)^{2}$. Also its graph is presented.

a. Calculate the outflow velocity at $t=40$.

b. (not included in TBI-3) In another barrel, a pump is used. The out-flow velocity can be expressed by the formula $V=40-\frac{1}{3} t$. At what moment will the out-flow velocity by pumping be equal to the out-flow velocity through a hole in the bottom?

The Monopoly task (used in TBI-1, -2, -4)

For a company, the revenue function is $R(q)=-0.5 q^{2}+12 q$ and the cost function is $T C(q)=0.03 q^{3}-0.5 q^{2}+4 q+15$.

a. For which amount of sold products do the costs increase at the slowest rate?

b. At what production level will the costs and the revenue increase at the same rate?

\section{The Costs task (used in TBI-3)}

The formula $T C=0.05 q^{3}-1.5 q^{2}+20 q+500$ describes the total costs, depending on the amount of sold products. What is the meaning of $T C^{\prime}(20)$ ?

Fig. 1 Short descriptions of the Barrel task, the Monopoly task and the Costs task

recurred in the interviews, we can compare across interviews and observe how Andy's instrumentation schemes developed over time. We expected to observe several techniques for solving each task: using the symbolic derivative, determining the steepness of the graph, drawing a tangent line to find instantaneous rate of change, using tiny intervals (with or without graphing calculator) or using several options of the GC, such as the $\mathrm{d} y / \mathrm{d} x$-option, the Tangent-option or the Nderiv-option. The Costs task was included in our analysis since it used the prime notation $\left(f^{\prime}\right)$, unlike the other tasks, which could possibly trigger an association to $f^{\prime}$ and, hence, to working symbolically without using a GC.

In each interview, after the task-based part, we asked a few open questions about the way Andy used the GC in mathematics and other classes. This gave us insight into his preferences and attitudes with respect to the GC.

All interviews were videotaped and transcribed afterwards. The use of the GC was recorded on video. However, the camera did not zoom-in on buttons or the screen. Instead, the interviewer made field notes of the screens used (e.g. calculation screen or graphing screen), the calculations made, the options used (e.g. intersect, trace), the window settings used and the formulas entered into the GC. 


\section{Data Analysis}

In order to describe Andy's instrumental genesis, we identified the instrumentation schemes in the subsequent interviews. Consequently, we analyzed the interview transcripts, Andy's written answers to the tasks and field notes on his GC use. An analysis of the use of artefacts can be carried out at different levels. For example, to use a certain GC option for calculating a point of intersection, a student needs several basic-level instrumentation schemes, such as to fill in formulas correctly, to find a proper window for the plot, and so forth. So, an instrumentation scheme can consist of instrumentation schemes described at different grain sizes.

We describe Andy's instrumentation schemes at two levels. Firstly, we look at the separate techniques he used to solve a task, identifying each technique, describing conceptual and technical elements of his knowledge, together with GC screens and options used, and offering his statements that explain why he used this technique. This gives insight into his instrumentation scheme related to that technique. Secondly, we offer an overview over several techniques he used to solve one and the same task and at the relationships between the techniques that he used, to provide insight into Andy's instrumentation scheme related to a certain type of task.

So, several instrumentation schemes, each related to a specific technique, together form an instrumentation scheme related to a type of task. The derivative framework as presented in Table 1 is used to analyze which representations and layers of the derivative framework are central in Andy's instrumentation scheme. The instrumentation schemes in subsequent interviews give us a look at his instrumental genesis.

The focus of this study is on Andy's instrumentation schemes in the task-based interviews. However, we also collected data to contrast him with his peers and with the taught content. Therefore, we analyzed how derivatives and instantaneous change were part of the taught content in Andy's class of grades 10, 11 and 12, and what characterizes his work in classes and on tests. This analysis is based on the following sources:

(1) Study planners and textbooks of Andy's mathematics and physics classes.

(2) Notebooks from his mathematics and physics classes.

(3) His answers to mathematics (calculus) and physics tests (force and motion) in grades 10,11 and 12 .

(4) Interviews with his mathematics and physics teachers in grades 11 and 12.

The analysis of these data focused on when and how aspects of the concept derivative were introduced, the role of various representations in Andy's mathematics and physics classes and how the GC was introduced and used by the teachers. The data analysis is based on representations and layers of the concept of derivatives (see Table 1). Additionally, we will contrast Andy's work in the task-based interviews with the repertoire of techniques used by his peers in terms of the framework of Table 1. For this, we will summarize results from Roorda (2012). 


\section{Results}

We present the results in chronological order.

\section{The Taught Content and Andy's Work in Grade 10, Before TBI-1}

When Andy was in grade 10, the concept of derivative was not yet introduced in his mathematics classes. However, in Andy's physics classes the concept of velocity was introduced by a graphical approach to determine instantaneous velocity on a distancetime graph (see Fig. 2), namely drawing a tangent to it, then drawing a large rectangular triangle to the tangent and then calculating the slope of the tangent. In terms of the framework presented in Table 1, this is a graphical approach at layer 3 without explicating relationships with other layers and representations of derivatives. From Andy's notebooks, and his work on the grade 10 physics test on kinematics, we observe him practicing this technique. There is no evidence that graphing utilities of the GC were used or mentioned in his physics classes, but in his mathematics classes the GC was used for plotting graphs.

\section{Results of Task-Based Interview 1 (April, Grade 10)}

After reading the Barrel-a task (out-flow velocity at one instant), Andy first considered drawing a tangent in the diagram on the worksheet. He then decided to work out the volumes at $t=40$ and $t=41$ in the calculation screen of his GC and subtract one from the other. He remarked that this value is not the exact answer, because the difference between two points is not exactly equal to the velocity at one point. So, he calculated the average rate of change over a unit interval.

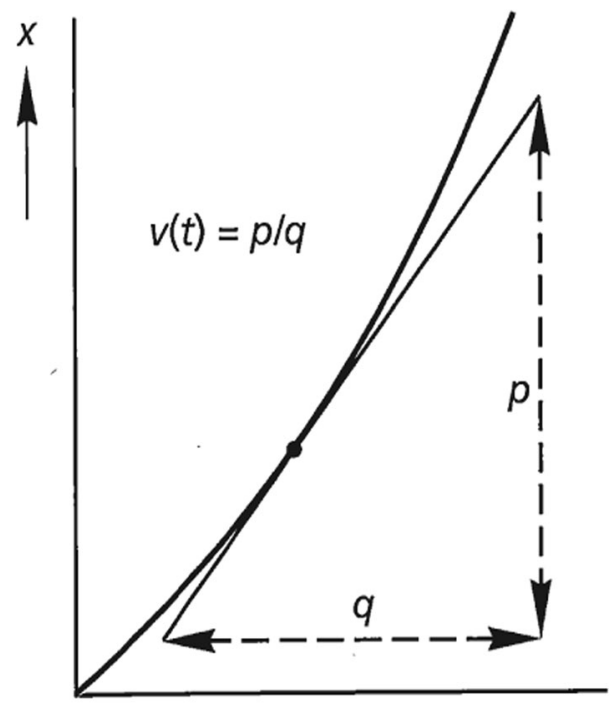

Fig. 2 Drawing a tangent as taught in Andy's physics classes: to calculate instantaneous velocity, a tangent is drawn and the slope $\mathrm{p} / \mathrm{q}$ is calculated (Middelink et al. 1998) 
In the Barrel-b task, Andy decided to plot both graphs with his GC: "I think they will intersect when there is the same amount of fluid in both barrels". After finding correct window settings, he studied both graphs and added the linear graph of $V$ to the diagram on the worksheet. By drawing a parallel tangent to the curved graph (see Fig. 3), he estimated that, at $t=60$, the out-flow velocity of both barrels would be equal. He checked this estimation by using the trace option of the GC to move to the volume at $t=60$ and $t=61$ and calculated their differences.

With the Monopoly-a task, Andy used the trace option again (see Fig. 4) to look stepwise where the costs increase least. For the subsequent Monopoly-b task, he plotted the graphs of $T C$ and $R$. He used the option Intersect to find the two points of intersection. He then remarked that what he did is not correct, because "the task is about increase". He had no idea how to proceed.

Table 2 summarizes our proposals with regard to Andy's instrumentation schemes related to tasks of the type 'to calculate an instantaneous rate of change'. They were dominated by numerical and graphical representations at layer 2 by using a unit interval, and at layer 3 by drawing a tangent. Instrumentation schemes at layer 2 were a trace scheme and a trace-value scheme. The core operational invariant is the understanding of derivatives as the increase of the function value per increase of the independent variable, as represented in both graphical and numerical ways.

Andy was well aware that his approach yielded an approximation. He related his trace-value scheme to his tangent scheme, by saying that the velocity at one point was not exactly the same as the increase over a unit interval. Also, after finding an answer by means of a tangent, he then checked his answer by calculating the decrease over a unit interval.

At the time of the interview, derivatives had not yet been introduced in his mathematics lessons. So, the two trace schemes were most likely based on Andy's understanding that an increase over a unit interval yields an approximation to the instantaneous rate of change. His tangent scheme was most probably based on physics lessons, in which tangents were used to find instantaneous velocity.

Andy's repertoire comprised of three schemes. One of the nine students also applied the graphical tangent scheme and another student used a numerical technique at layer 2 , calculating $V(41)-V(40)$. The remaining seven students had no means whatsoever to calculate or approximate instantaneous rates of change for the given tasks. Clearly, none of the students could use symbolic techniques, because derivatives had not yet been introduced. In the mathematics classes, all had learnt to use the GC for plotting functions, but none of them used tracing in TBI-1. Andy was the only student whose
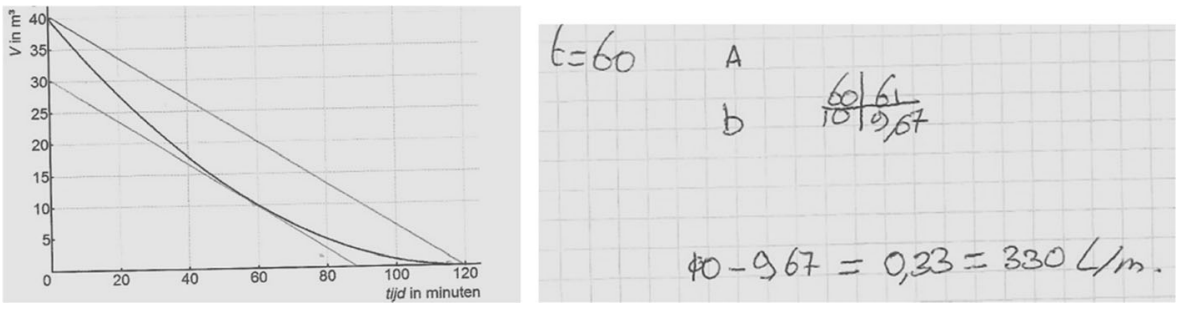

Fig. 3 Drawing and calculation of Andy in the Barrel-b task. The Dutch convention for writing numbers prescribes the use of a comma instead of a period between the unit and the tenths 


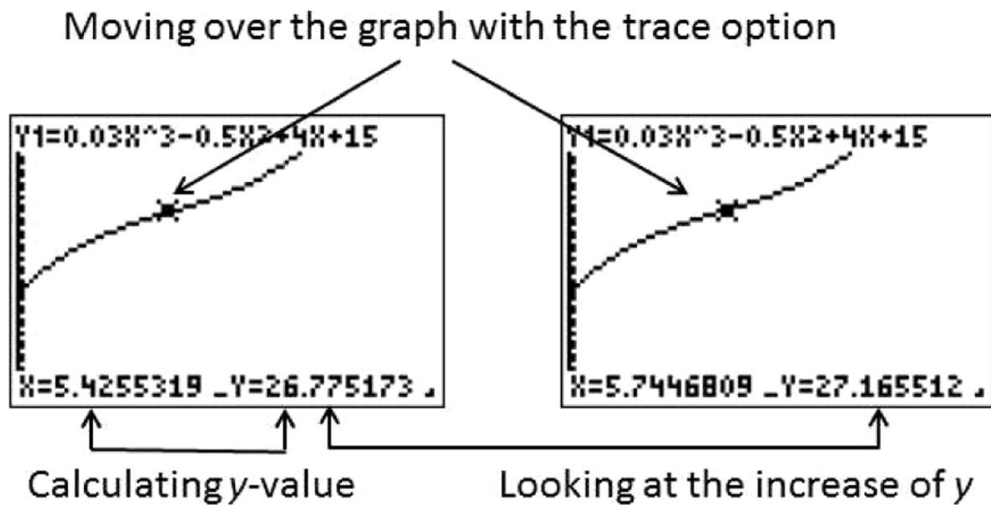

Fig. 4 An example of Andy's trace scheme

repertoire comprised of more than one scheme with a variety of representations (both graphical and numerical) and the GC played a central role in it.

\section{The Taught Content and Andy's Work in Grade 11, Before TBI-2}

In Andy's mathematics classes, the concept of derivative was introduced at the beginning of grade 11. The chapter on derivatives started with the transition from a difference quotient to a differential quotient. The first page showed distance-time functions and graphs, an average rate of change was given meaning as the average velocity over an interval and instantaneous rate of change as the velocity at one instant in time. Thereafter, the slope of the tangent at a graph in the $x-y$-plane was approximated by the slope of an increasingly smaller secant line. Thus, the derivative was first

Table 2 Overview of the schemes developed by Andy in TBI-1

\begin{tabular}{|c|c|c|c|}
\hline $\begin{array}{l}\text { Instrumentation } \\
\text { scheme }\end{array}$ & Techniques & Conceptual elements & Technical elements \\
\hline Tangent scheme & $\begin{array}{l}\text { Draw a tangent on } \\
\text { paper. }\end{array}$ & $\begin{array}{l}\text { Rate of change is related to the } \\
\text { steepness of the graph: the } \\
\text { steepness of a tangent } \\
\text { represents the steepness of } \\
\text { the graph at one point. }\end{array}$ & $\begin{array}{l}\text { Calculate the differences of } \\
y \text { and } x \text { and calculate } \frac{\Delta y}{\Delta x} \text {. }\end{array}$ \\
\hline Trace scheme & $\begin{array}{l}\text { Plot the graph, move } \\
\text { the cursor over the } \\
\text { graph and look at } \\
\text { the increase in } y \text {. }\end{array}$ & $\begin{array}{l}\text { To find a minimum increase } \\
\text { look at the slowest increase } \\
\text { of subsequent } y \text {-values. }\end{array}$ & $\begin{array}{l}\text { Plot the graph, press trace } \\
\text { and scroll over the } \\
\text { graph. } \\
\text { The trace option gives pairs } \\
\text { of } x \text { - and } y \text {-values. The } \\
\text { GC makes equal steps in } \\
\text { the } x \text {-values. }\end{array}$ \\
\hline $\begin{array}{l}\text { Trace-value } \\
\text { scheme }\end{array}$ & $\begin{array}{l}\text { Calculate the values } \\
\text { with the GC and } \\
\text { look at the increase } \\
\text { over a unit interval. }\end{array}$ & $\begin{array}{l}\text { The increase over a unit } \\
\text { interval is an approximation } \\
\text { to the instantaneous rate of } \\
\text { change. }\end{array}$ & $\begin{array}{l}\text { In the trace option, put in an } \\
x \text {-value, press 'enter' and } \\
\text { then the GC calculates } \\
\text { the corresponding } \\
y \text {-value. }\end{array}$ \\
\hline
\end{tabular}


linked to physics and real-world phenomena, and thereafter to the slope of the tangent to the graph. In this introduction, graphical, numerical and symbolic representations were all used, but this introduction spanned only one lesson. Thereafter, the basic differentiation rules were introduced and practiced.

Andy's notebook shows that he spent a lot of time calculating derivatives symbolically to find extremes of functions or formulas for tangent lines (see Fig. 5).

In the interview, Andy's mathematics teacher said that in her teaching she mentioned only incidentally how the GC could be used, and she told the class that plotting graphs would be helpful to understand the function. Also, she mentioned some options of the calc-menu of the GC, such as 'intersect' (to find the coordinates of the points of intersection of two graphs), and ' $\frac{\mathrm{d} y}{\mathrm{~d} x}$ ' (to find the slope of a tangent). Figure 6 shows an excerpt of Andy's notebook about the $\frac{\mathrm{d} y}{\mathrm{~d} x}$ option, in which he wrote down the steps to find the slope of a tangent using the GC.

In the test on the calculus chapter, three weeks before TBI-2, we noticed that Andy was able to calculate the derivative of polynomials symbolically, such as $O(p)=4 p^{2}-$ $p^{3}$ and $f(x)=x^{3}-3 x^{2}-9 x$, without using a GC, but also that he sometimes used his GC to calculate a zero, a point of intersection or a maximum. The teacher commented on Andy's answer to the test: "You should work algebraically; GC use provides no points, even if your answer is correct". Thus, on the one hand, the teacher gave access to the $\mathrm{GC}$, but on the other she discouraged its use. One task in the test asked for the velocity of a falling object. Although it was a mathematics test on derivatives, Andy solved this task with a rule learnt in his physics classes. His grade on the mathematics test was extremely low (2.4 out of 10) and his skill at calculating and using derivatives seemed weak.

\section{Results of Task-Based Interview 2 (November, Grade 11)}

TBI-2 was held in November, a few weeks after the introduction of derivatives.

To calculate the out-flow velocity in the Barrel-a task, Andy started by plotting the graph on his GC and by using the $\mathrm{d} y / \mathrm{d} x$ option in the calc-menu, came up with a correct answer. When asked to check his answer, he mentioned: drawing a tangent on the

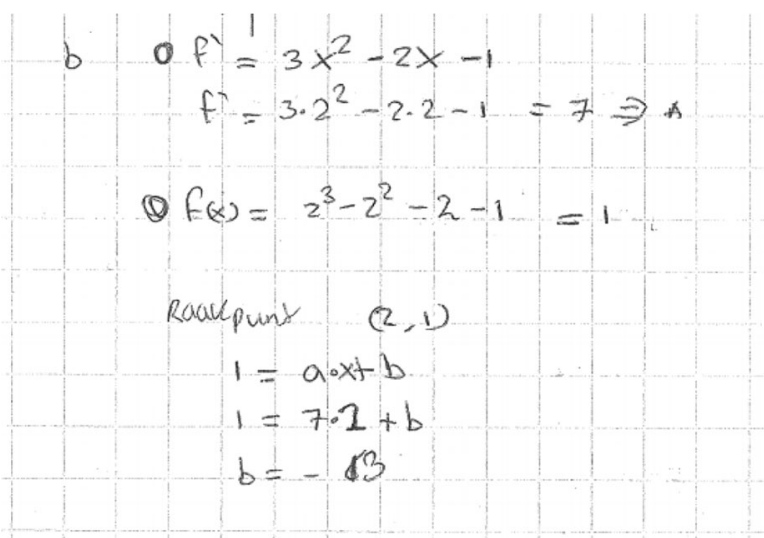

Fig. 5 Andy's calculation of the tangent to $f(x)=x^{3}-x^{2}-x-1$ at the point $x=2$ 


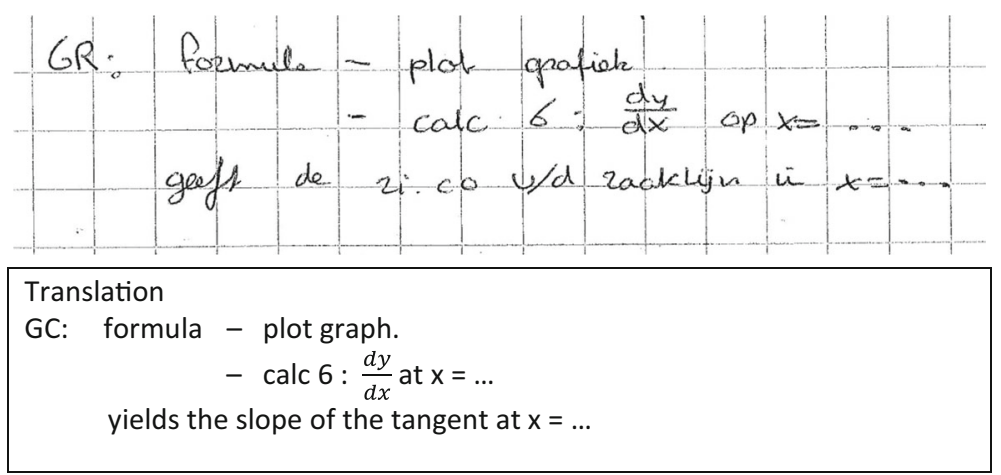

Fig. 6 Summary of using the GC in Andy's notebook

worksheet and calculating its slope (by taking two distant points on that tangent line), and calculating the difference quotient over a tiny interval (he entered $t=40$ and $t=40.0001$ into his GC to find the corresponding values of $V$ ). He did not calculate the difference quotient correctly, because he confused the numerator and the denominator and calculated $\frac{\Delta t}{\Delta V}$. Later on in the interview, he discovered his mistake and corrected it. He remarked about this tiny interval: "It is somewhat the same as dx-dy, dy-dx [option of GC], but then calculated by hand".

In the Barrel-b task, Andy estimated the answer $t=60$ by looking at the graph in his GC. He checked with calc- $\mathrm{d} y / \mathrm{d} x$ whether the slope at $t=60$ was exactly -.333333 . The interviewer asked if he were able to calculate the answer, instead of estimating. Andy said: "To find this value in a direct way? [...] The line is always $1 / 3$, so you have to find a point on the other graph where it is the same".

Andy used the $\mathrm{d} y / \mathrm{d} x$-option again in the Monopoly task, where he estimated the point where the increase of the graph is minimal by moving over the plot and reading off the calc-dy/dx values. In the Monopoly-b task, he estimated the $x$-value, for which the steepness of both graphs is equal. He made his cursor jump up and down between the two graphs, using the $\mathrm{d} y / \mathrm{d} x$-option for calculating the steepness (see Fig. 7). It was time-consuming and he commented: "I have no idea how to do this in another way". Andy did not mention the derivative function in any of the tasks.

Table 3 summarizes our proposed instrumentation schemes for Andy's calculating of the instantaneous rate of change, which was dominated by the GC option calc- $\mathrm{d} y / \mathrm{d} x$. The earlier trace and trace-value schemes (used in TBI-1: see Table 2) were replaced. The use of calc-dy/dx was combined with inspection of the graphs and estimating points by looking at the $\frac{\mathrm{d} y}{\mathrm{~d} x}$ values that the GC generated in the plot window, identifying them as the steepness of the graph at different places (see Fig. 7). In his explanations, Andy related calc- $\mathrm{d} y / \mathrm{d} x$ to the tangent and also to the increase of the function over a tiny interval. Actually, he linked the tiny-interval technique explicitly to the calc-dy/dx option, by stating that the GC also uses tiny intervals to generate $\frac{\mathrm{d} y}{\mathrm{~d} x}$-values.

Central aspects of his instrumentation scheme of instantaneous rate of change were, just as in TBI-1, the numerical and graphical representations. However, these were now at layer 3, as we interpret his change from unit intervals (in TBI-1) to tiny intervals (in TBI-2) as a limiting process. In the numerical representation, Andy related layer 2 and 


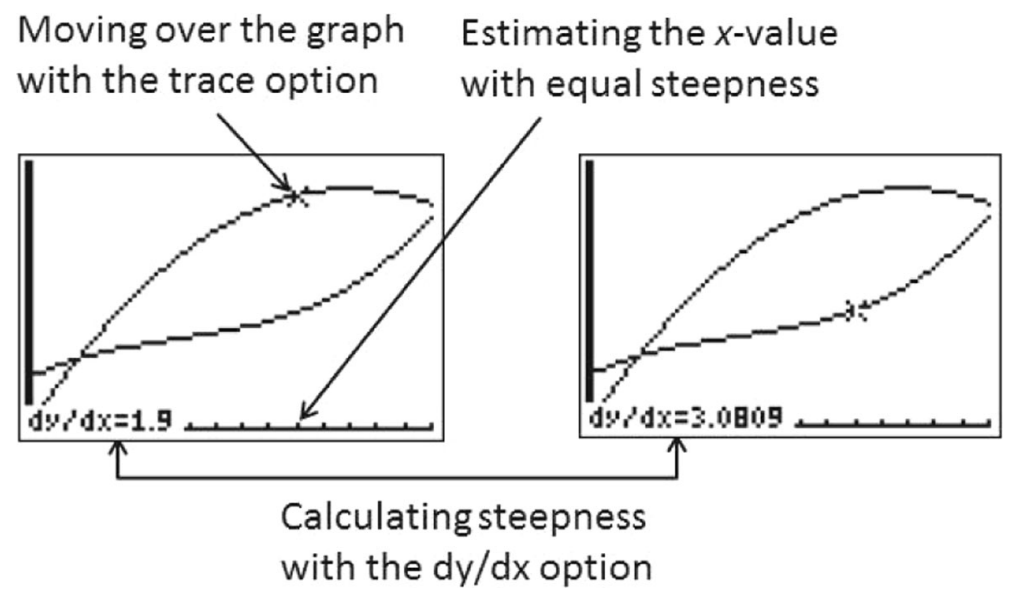

Fig. 7 An example of the calc-dy/dx scheme

layer 3 by linking the tiny-intervals technique to instantaneous rate of change. We observe that in the symbolic representation this link from layer 2 to layer 3 was weak: Andy often called the option of his GC the $\mathrm{d} x / \mathrm{d} y$ option (note the incorrect order) and he also calculated a difference quotient by using the reciprocal fraction $\frac{\Delta t}{\Delta V}$. In short, the core operational invariant is an understanding of the derivative as the average increase of the function over a tiny interval, calculated through the calc- $\mathrm{d} y / \mathrm{d} x$ technique.

When asked for other approaches for these tasks, not once did Andy mention the use of derivatives. To him, differentiation was apparently not related to the trace-value scheme and the calc- $\mathrm{d} y / \mathrm{d} x$ scheme. Andy preferred using the GC, stating: "Plotting graphs is quite handy, because you get a good picture of the situation [...] especially the calc-menu is practical".

Table 3 Overview of the schemes developed by Andy in TBI-2

\begin{tabular}{|c|c|c|c|}
\hline $\begin{array}{l}\text { Instrumentation } \\
\text { scheme }\end{array}$ & Techniques & Conceptual elements & Technical elements \\
\hline $\begin{array}{l}\text { Calc-d } y / \mathrm{d} x \\
\text { scheme }\end{array}$ & $\begin{array}{l}\text { Use the GC option } \\
\qquad \mathrm{d} y / \mathrm{d} x\end{array}$ & $\begin{array}{l}\text { Velocity at one moment can be } \\
\text { calculated by the dy/dx } \\
\text { option. } \\
\text { The same holds true for } \\
\text { increase at one point of the } \\
\text { graph. }\end{array}$ & $\begin{array}{l}\text { Plot the graph, press option } \\
\mathrm{d} y / \mathrm{d} x \text {, press the } x \text {-value } \\
\text { and press Enter. }\end{array}$ \\
\hline Tangent scheme & $\begin{array}{l}\text { Draw a tangent on } \\
\text { paper. }\end{array}$ & $\begin{array}{l}\text { Rate of change is related to } \\
\text { steepness of the graph. } \\
\text { The steepness of a tangent } \\
\text { represents the steepness of } \\
\text { the graph at one point. }\end{array}$ & $\begin{array}{l}\text { Calculate the differences in } y \\
\text { and } x \text { and calculate } \frac{\Delta y}{\Delta \mathrm{x}} \text {. }\end{array}$ \\
\hline $\begin{array}{l}\text { Trace-value } \\
\text { scheme }\end{array}$ & $\begin{array}{l}\text { Calculate the values } \\
\text { with the GC and look } \\
\text { at the increase over a } \\
\text { tiny interval. }\end{array}$ & $\begin{array}{l}\text { The average increase over a } \\
\text { tiny interval is an } \\
\text { approximation of the } \\
\text { instantaneous rate of } \\
\text { change. }\end{array}$ & $\begin{array}{l}\text { In the trace option, put in an } \\
x \text {-value, press Enter and the } \\
\text { GC will calculate the } \\
\text { corresponding } y \text {-value. }\end{array}$ \\
\hline
\end{tabular}


Andy's repertoire in TBI-2 comprised three different schemes, none of which was symbolic. Out of his nine peers, most used one or two techniques, of which the graphical tangent technique was used or mentioned by seven of them. There were four students who used the derivative, but three of these did so inaccurately. Apparently, so shortly after its introduction, a considerable number of students were not yet able to use the derivative in the interview. Thus, Andy's obliviousness concerning derivatives in TBI-2 was not in great contrast to his peers. However, just like in TBI-1, he stood out for the breadth of his repertoire and his GC use that he may have learnt from his teacher. However, not one of the other students had picked up the Calc-menu in the same way as Andy.

\section{The Taught Content and Andy's Work in Grade 11, Before TBI-3}

In the second half of grade 11, differential calculus was extended to differentiation rules (product and quotient rule) and its application to special functions (e.g. logarithms) in Andy's mathematics classes. The differentiation rules were introduced through the symbolic limit definition. Derivatives were mostly used to calculate extreme values and formulas of tangents, such as, calculate the extremes of $f(x)=\frac{x}{\ln (x)}$ or find the equation of the tangents to the graph of $f(x)=(2 x+1) \mathrm{e}^{x}$ which pass through $(0,0)$. Most tasks were expected to be solved algebraically without use of the GC. Sometimes graphs were used to check an answer.

In the interview, the mathematics teacher said that the focus in the calculus lessons was on algebraic manipulations. The GC was only used to plot graphs and sometimes to check answers. So, in terms of the framework, the teacher's explanations and the textbook both emphasized the symbolic representation at layer 3 and 4 (derivative at one point and derivative function) and the graphical representation at layer 3 (tangent).

On a grade 11 test in March, Andy was able to calculate derivatives, to find extreme values and tangents, but often he also rounded off calculated values instead of giving exact values (see Fig. 8).

\section{Results of Task-Based Interview-3 (May, Grade 11)}

We report on Andy's work on the Barrel-a and Costs tasks. Neither the Barrel-b task nor the Monopoly task was included in this interview.

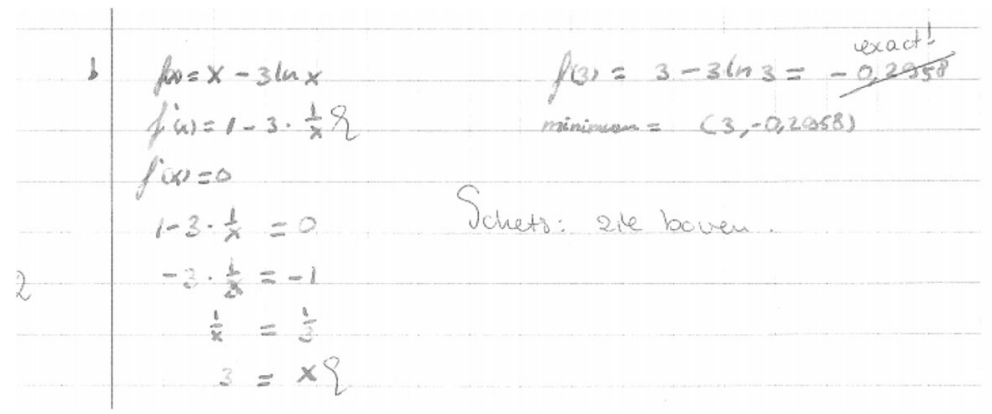

Fig. 8 Andy's calculus test: solution of the task to calculate the minimum of $f(x)=x-3 \ln (x)$ 
To calculate the out-flow velocity in the Barrel-a task, Andy used the same techniques as in TBI-2, although in a different order. He started by drawing a tangent to the graph at the worksheet and calculating its slope. He proceeded by plotting the graph on his GC and used the $\mathrm{d} y / \mathrm{d} x$ option to find a correct answer. He remarked, "Another way is to substitute the formula into the GC. You will get the graph and then you can calculate the slope with $\mathrm{d} x / \mathrm{d} y$ at $t=40 "$ (see Fig. 5). Finally, he calculated the difference quotient on a tiny interval, saying: "Without plotting, I can calculate this answer also by hand, by using for example $t=40.001$ and $t=40$ ". Andy wrote down 40.001 and 40.000 (see Fig. 9), and said, "That is also what the calculator does, but the GC does it very small". He changed the number 40.001 to 40.000001 . Again, he did not mention that differentiation rules could be used to find the out-flow velocity.

In the Costs task, Andy mentioned symbolic differentiation for the first time. After reading the question, which included the prime notation $T C^{\prime}(20)$, Andy remarked, "The prime will be placed there for a good reason, I have to fill in 20 into the derivative". The interviewer asked for the meaning of the answer. Andy stated, "You calculate the slope of the tangent at $q=20$, the decrease, when you put it into the graph". Andy determined the derivative function and filled in $q=20$. Because of a typo in the formula, he got an incorrect answer. So he checked his answer by using calc- $\mathrm{d} y / \mathrm{d} x$. He was convinced that this GC answer was correct, and not his own calculation.

Table 4 summarizes the proposed schemes used by Andy. Just like in TBI-2, Andy used three techniques to calculate the out-flow velocity in the Barrel task - and again he did not refer to the derivative. However, in the Costs task, he related calc- $\mathrm{d} y / \mathrm{d} x$ to differentiation - it was the first time we observed him doing this, and it was most probably triggered by use of the prime notation (') in the task. Point of reference was the slope of the tangent, because, according to Andy, the slope could be calculated with his GC as well as with symbolic differentiation.

Central to his instrumentation scheme remained the calc- $\mathrm{d} y / \mathrm{d} x$ scheme. This is related to the tangent scheme and also to the trace-value scheme over a tiny interval. Again the graphical and numerical layer 3 aspects were central. Also, it is noteworthy that Andy mixed up the order of the division, as at several instances he spoke about $\mathrm{d} x$ / $\mathrm{d} y$ instead of $\mathrm{d} y / \mathrm{d} x$. In this interview we saw Andy linked the symbolic derivative (layer 4) to the graphical layer 3 (steepness of the graph) in the Costs task. Altogether, the

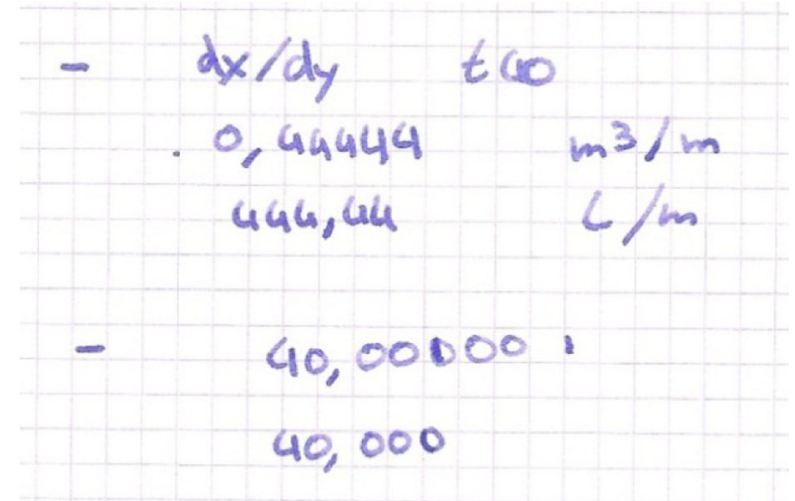

Fig. 9 Andy's notes in TBI-3 in the Barrel-a task 
Table 4 Overview of the schemes developed by Andy in TBI-3

\begin{tabular}{|c|c|c|c|}
\hline $\begin{array}{l}\text { Instrumentation } \\
\text { schemes }\end{array}$ & Techniques & Conceptual elements & Technical elements \\
\hline Calc-d $y / \mathrm{d} x$ scheme & $\begin{array}{l}\text { Use the GC option } \\
\mathrm{d} y / \mathrm{d} x\end{array}$ & $\begin{array}{l}\text { Velocity at one moment can be } \\
\text { calculated by the option } \mathrm{d} y / \mathrm{d} x \text {. } \\
\text { The same holds for increase at } \\
\text { one point of the graph. }\end{array}$ & $\begin{array}{l}\text { Plot the graph, press option } \\
\mathrm{d} y / \mathrm{d} x \text {, press the } x \text {-value } \\
\text { and press Enter. }\end{array}$ \\
\hline Tangent scheme & $\begin{array}{l}\text { Draw a tangent on } \\
\text { paper. }\end{array}$ & $\begin{array}{l}\text { Rate of change is related to } \\
\text { steepness of the graph. } \\
\text { The steepness of a tangent } \\
\text { represents the steepness of } \\
\text { the graph in one point. }\end{array}$ & $\begin{array}{l}\text { Calculate the differences of } \\
y \text { and } x \text { and calculate } \frac{\Delta y}{\Delta x} .\end{array}$ \\
\hline $\begin{array}{c}\text { Trace-value } \\
\text { scheme }\end{array}$ & $\begin{array}{l}\text { Calculate the increase } \\
\text { over a tiny interval. }\end{array}$ & $\begin{array}{l}\text { The average increase over a tiny } \\
\text { interval is an approximation } \\
\text { of the instantaneous rate of } \\
\text { change. }\end{array}$ & $\begin{array}{l}\text { In the trace option put in a } \\
x \text {-value, press Enter and } \\
\text { the GC calculates the } \\
\text { corresponding } y \text {-value. }\end{array}$ \\
\hline $\begin{array}{l}\text { Symb-deriv } \\
\text { scheme }\end{array}$ & $\begin{array}{l}\text { Calculate symbolically } \\
\text { the derivative for the } \\
\text { given } x \text {-value. }\end{array}$ & $\begin{array}{l}\text { The value of the derivative is } \\
\text { the slope of the tangent. }\end{array}$ & No technical elements. \\
\hline
\end{tabular}

operational invariants are an understanding of the derivative as the average increase of the function over a tiny interval, calculated through calc-d $y / \mathrm{d} x$, through graphical approaches or eventually through the derivative and filling in the point.

When the interviewer asked at the end of TBI-3 whether he used his GC often in mathematics classes, Andy replied, "Yes, I normally use the GC; algebraic calculations are more difficult for me". This judgment of his own algebraic calculation skills probably affected his choice of techniques to solve the tasks.

Andy's repertoire in TBI-3 comprised four different schemes, one of which used the derivative. Out of his nine peers, there were seven students who used the derivative, and they did that for a variety of tasks, not just when prompted by the prime notation ('). Four of these students used the derivative inaccurately, making errors just like Andy's. His peers were able to use or make mention of another technique, mostly the graphical tangent one. Andy was the only student who used GC options. Moreover, he used them with a variety of schemes.

\section{The Taught Content and Andy's Work in Grade 12, Before TBI-4}

The fourth interview was held in November, when Andy was in grade 12. For a year, he had been working on tasks applying differentiation rules. From his textbook, his notebook and the work on tests, we can see that derivatives were a recurring topic, because the chain rule, the second derivative and inflection points were introduced. On a grade 12 test in November, one of the tasks was to calculate the minimum and the inflection point of the function $f(x)=\ln \left(2 x^{2}+3\right)$. Andy calculated the derivative correctly, but he failed to calculate the minimum and the inflection point. He made mistakes in his algebraic calculations and often rounded off calculated values: his ability to work symbolically with derivatives remained weak. 


\section{Results of Task-Based Interview 4 (November, Grade 12)}

Andy solved the Barrel-a task in nearly the same way as in TBI-3. First, by drawing a tangent on the worksheet; second, by using calc- $\mathrm{d} y / \mathrm{d} x$. Third, Andy again stated that he could use a tiny interval and he wrote: ' $\mathrm{d} x$ - $\mathrm{d} y$ by hand, point 40 and 40.001 ' (note the incorrect order of $\mathrm{d} x-\mathrm{d} y$ ). In the Barrel-b task, Andy equated the formulas for the volumes (so, he was not looking at steepness) and he plotted the two volume graphs. By using the option Intersect, he found two points of intersection ( $x=0$ and $x=120)$, which have no meaning in terms of the posed question.

In the Monopoly-a task, Andy decided to work with differentiation rules, and this time he is not prompted by prime notation. So, he works symbolically, albeit with his GC: to find the slowest rate of increase Andy plotted the derivative graph (of $T C^{\prime}$ ) and, using the GC option Minimum, he determined $x=5.6$ as the point with the slowest rate of increase. To check his answer, he calculated with calc- $\mathrm{d} y / \mathrm{d} x$ the slope at $x=5.6$, concluding, "the increase at this point is not much". In the Monopoly-b task, Andy used the graphs of the derivatives again, but this time he interpreted these graphs incorrectly, because, after plotting the derivative graphs (see Fig. 10), he wondered: "They have to increase with the same rate, but one graph is going down and the other graph is going up, so there is no point where both graphs increase". So, Andy mixed up the graphs of the $T C$ and $T C^{\prime}$ : instead of looking at the point of intersection of the derivative graphs, he reasoned about the behaviour of the derivative graph.

Because TBI-4 was the final interview in this longitudinal study, the interviewer asked a few short retrospective questions. Andy stated that he often uses the GC, because "it is faster when you do understand it [...] especially when you have to solve equations, [...] you make easier mistakes in formulas compared with the intersect option of the GC".

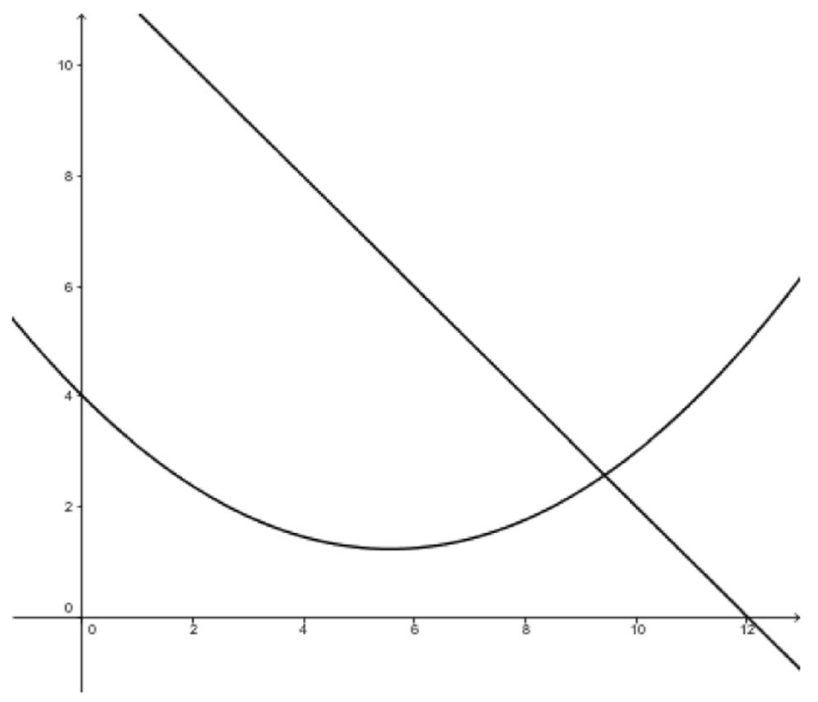

Fig. 10 Andy plots the graphs of the derivative of $T C$ and $R$ 
The interviewer asked why he did not use derivatives in the Barrel task. Andy first replied: "Didn't I use a derivative? I did use it [...] I drew a tangent - oh, the derivative, but, the dx-dy option is the option of the GC to calculate derivative, I know how to do it". So, even when explicitly asked, he referred to the derivative in graphical and GC terms. Later on, he explained that symbolic derivatives were not so clear to him at first, but also that he could have used derivatives in the last two interviews. As an explanation for not using symbolic differentiation, he surmised that it was perhaps a more difficult way of solving the tasks.

Table 5 summarizes the proposed schemes used by Andy.

In the final interview, Andy's instrumentation scheme of instantaneous rate of change was again dominated by the calc- $\mathrm{d} y / \mathrm{d} x$ scheme. Just as in TBI-2 and TBI-3, the same three techniques, calc-d $y / \mathrm{d} x$, tangent and tiny interval were observed, and the corresponding actions seemed to be connected in his instrumentation scheme. In his notebook we observed that he practiced many differentiation rules for many different functions, but he referred to symbolic derivatives only once. And when he did, it was again GC-based.

Sometimes, links between layer-3 techniques and symbolic differentiation became visible. For example, in the Monopoly tasks, Andy used the graph of the derivative function to find a point of minimal increase (Monopoly-a task) and also to find points with equal increase (Monopoly-b task). In the Monopoly-a task, Andy interpreted the graph of $T C^{\prime}$ correctly, but in the Monopoly-b task he mixed up the steepness of the graph and the steepness of the graph of the derivative. This shows a weak link between the symbolic representation at layer 4 and the graphical representations at layer 3 and 4 . The main operational invariants are unchanged.

Table 5 Overview of the schemes developed by Andy in TBI-4

\begin{tabular}{|c|c|c|c|}
\hline $\begin{array}{l}\text { Instrumentation } \\
\text { scheme }\end{array}$ & Techniques & Conceptual elements & Technical elements \\
\hline $\begin{array}{l}\text { Calc-d } y / \mathrm{d} x \\
\text { scheme }\end{array}$ & Use the GC option $\mathrm{d} y / \mathrm{d} x$. & $\begin{array}{l}\text { Velocity at one moment can } \\
\text { be calculated by the option } \\
\mathrm{d} y / \mathrm{d} x \text {. } \\
\text { The same holds for increase } \\
\text { at one point of the graph. }\end{array}$ & $\begin{array}{l}\text { Plot the graph, press option } \\
\mathrm{d} y / \mathrm{d} x \text {, press the } x \text {-value } \\
\text { and press Enter. }\end{array}$ \\
\hline Tangent scheme & Draw a tangent on paper. & $\begin{array}{l}\text { Rate of change is related to } \\
\text { steepness of the graph. } \\
\text { The steepness of a tangent } \\
\text { represents the steepness } \\
\text { of the graph in one point. }\end{array}$ & $\begin{array}{l}\text { Calculate the differences of } \\
y \text { and } x \text { and calculate } \frac{\Delta y}{\Delta x} \text {. }\end{array}$ \\
\hline $\begin{array}{l}\text { Trace-value } \\
\text { scheme }\end{array}$ & $\begin{array}{l}\text { Calculate the increase } \\
\text { over a tiny interval. }\end{array}$ & $\begin{array}{l}\text { The average increase over a } \\
\text { tiny interval is an } \\
\text { approximation of the } \\
\text { instantaneous rate of } \\
\text { change. }\end{array}$ & $\begin{array}{l}\text { In the trace option put in } \\
\text { an } x \text {-value, press Enter } \\
\text { and the GC will calculate } \\
\text { the corresponding } y \text {-value. }\end{array}$ \\
\hline $\begin{array}{l}\text { Calc-min } \\
\text { scheme }\end{array}$ & $\begin{array}{l}\text { Plot the derivative graph } \\
\text { and calculate the } \\
\text { minimum of this } \\
\text { graph with the GC. }\end{array}$ & $\begin{array}{l}\text { The } x \text {-value of the minimum } \\
\text { of the derivative graph } \\
\text { gives the point with } \\
\text { minimal steepness. }\end{array}$ & $\begin{array}{l}\text { Plot the graph. Press the } \\
\text { calc-min button to find } \\
\text { the minimum. }\end{array}$ \\
\hline
\end{tabular}


Andy's repertoire in TBI-4 comprised four different schemes. For one of these, the calc-min scheme, he needed a derivative, after which he could use the GC again. His schemes differed from his peers. They frequently used the derivative, and the graphical tangent scheme (drawn on paper) came second. Three of his peers said that the GC could also be used for solving the tasks, but their GC competence did not compare with Andy's. Andy stood out as a student who, on the one hand, shunned the derivative, yet on the other used the GC with a variety of schemes.

In the final sub-section, we give an overview of the development of Andy's instrumentation schemes and also offer proposed explanations for his development.

\section{The Development of Instrumentation Schemes}

Table 6 provides an overview of the observed schemes in the various interviews. In TBI-1, before the introduction of derivatives, Andy's preferred instrumentation scheme was characterized as a trace scheme: he used the trace option of his GC to generate $y$-values from which he calculated their stepwise increase. After the introduction of derivatives, in TBI-2, we observe an uptake of the calc-d $y / \mathrm{d} x$ option of the GC. A characterization of his instrumentation scheme of 'instantaneous rate of change' is the relationship of a trace-value scheme, used by Andy to find the increase over a tiny interval, a tangent scheme and a calc-dy/dx scheme. These schemes are explicitly linked to each other by conceptual aspects, such as 'the steepness of a curved graph at one point can be found by a tangent' and 'velocity and increase in one point are related to steepness'. Central to Andy's instrumentation scheme of instantaneous rate of change are the graphical and numerical layer 3 cells of the derivative framework.

In TBI-3, the same schemes are central in the Barrel task. In the Costs task, a weak link occurred between symbolic differentiation and calc-d $y / \mathrm{d} x$. Part of Andy's instrumentation scheme of instantaneous rate of change is the understanding that calc- $\mathrm{d} y / \mathrm{d} x$ and symbolic differentiation can both be used to find the slope of a graph at a point. This seems to be the link between both techniques. In TBI-4, Andy again heavily relied on calc-dy/dx. Although in the final task he used symbolic derivatives, his ability in working in layer 4 with formulas and graphs of derivatives remained weak. He made calculation mistakes and interpretative ones of derivatives graphs, while he was confident about techniques related to graphical and numerical representations at layer 3 .

Table 6 The development of Andy's schemes

\begin{tabular}{llll}
\hline TBI-1 & TBI-2 & TBI-3 & TBI-4 \\
\hline Trace scheme & - & - & - \\
Tangent scheme & Tangent scheme & Tangent scheme & Tangent scheme \\
Trace-value scheme & Trace-value scheme & Trace-value scheme & Trace-value scheme \\
& Calc-d $y / \mathrm{d} x$ scheme & Calc-d $y / \mathrm{d} x$ scheme & Calc-d $y / \mathrm{d} x$ scheme \\
& & Symb-derive scheme & - \\
& & Calc-min scheme \\
\hline
\end{tabular}




\section{Conclusion and Reflections}

The central question in this article is which instrumentation schemes can develop while using a GC in learning about the derivative. We presented the results of one student, who is an intensive GC user. His case elicits how a student's understanding of the concept of derivative can be affected by the access to a GC. Tables 2, 3, 4, and 5 describe six different instrumentation schemes related to the concept of derivative at different stages in time. Conceptual aspects of the derivative and technical elements of the GC developed in interaction, such as using the trace option to estimate the steepness of a graph or the calc- $\mathrm{d} y / \mathrm{d} x$ option to calculate the derivative at a point. Table 6 describes the development of Andy's instrumentation schemes over the years. Three schemes became central: the tangent scheme, the trace-value scheme and the calc- $\mathrm{d} y / \mathrm{d} x$-scheme. One important conclusion, therefore, is that Andy's schemes maintained the operational invariant of understanding the derivative as an average change over a tiny interval that can be considered in a graphical or numerical way or through the calc- $d y / d x$ technique. These schemes seemed relatively stable and were hardly affected by symbolic differentiation techniques.

We have evidence of Andy's knowledge of the symbolic derivative and of his ability to apply differentiation rules, because we observed these from his notebooks and from his work on tests. From the mathematics tests and the teacher interviews we know that the teacher did not promote intensive GC use, which is reflected in the work by Andy's peers, who scarcely use the GC options. While Andy spent much time in mathematics classes practicing differentiation rules, often calculating tangents and extremes, he did not mention or use derivatives and differentiation rules in the TBIs, until he saw an instance of prime notation (') in one of the tasks.

Despite repeated questions by the interviewer about possible alternative approaches, Andy only once mentioned the derivative spontaneously in the final interview, but then again he used it in conjunction with the GC. From grade 10 onwards, Andy displayed a variety of schemes using options of the GC. Therefore, we conclude that these options of the GC have become part of his instrumentation schemes for situated tasks on rate of change, and that these seem to have developed separately from his understanding of the symbolic differentiation rules.

\section{Reflections on the Research}

The idea that use of the GC encourages students to create links between graphical and symbolical representations as reported in Burrill et al. (2002) and Delos Santos (2006) does not hold for Andy. His development over several years shows that the connection between symbolical and graphical representations remained weak, even in the final grade 12 interview.

This seems to be caused by the fact that the GC enables some transitions in the derivative framework, which "work well" for Andy. He often used the transition from a function (symbolic representation at layer 1) to steepness of the graph at one point (graphical representation at layer 3 ) through the $\mathrm{d} y / \mathrm{d} x$ option. So, his case shows that learning processes in mathematics education can be strongly affected by the access to a GC. Contrary to the conclusion of Delos Santos (2006), who observed that students do not fully integrate the GC in their mathematical activity, the case of Andy shows that 
the availability of the GC can lead to an instrumentation scheme with strongly integrated elements of mathematical knowledge and knowledge of the artefact.

It is still not clear to us why Andy's relationships between symbolic differentiation rules and graphical, numerical and GC techniques remained weak. We offer two related potential explanations.

(1) Andy's instrumentation schemes seem to be affected by his preference for physics, a subject in which he was a good student. There he learnt in grade 10 that the steepness of distance-time graphs can be used for approximations of velocity. The approach in his mathematics classes focused on tangents in the $x-y$-plane. The distinction between the two subjects seems to result in a separation between Andy's solutions. His solutions to the first type of tasks (on distance-time graphs) were often approximate, while the solutions in his notebooks to the latter type of tasks (tangents in the $x-y$-plane) always involved symbolic calculations. Andy was aware of the fact that answers of the GC were approximations. However, because the tasks in the interviews were all situated in contexts, Andy did not feel the need to find exact values by using differentiation rules.

(2) Andy had a preference for working with graphs. On several occasions, he expressed that graphs gave him an overview over the situation and they supported his understanding. For a graph-oriented student like Andy, the step from a tracevalue scheme to the calc-d $y / \mathrm{d} x$ option was easily made. For him, the use of calc$\mathrm{d} y / \mathrm{d} x$ was not meaningless button-pressing, but an insightful technique. As a consequence, Andy seemed to avoid symbolic manipulation, with which he often made algebraic errors. His work on the calculus tests showed that he was weak when working symbolically with derivatives. His uncertainty with respect to his algebraic manipulation ability, combined with his high level of understanding of graphs, may be an explanation for his preference for plotting graphs and subsequent use of his GC.

In an earlier analysis of Andy and his nine peers (Roorda 2012), based on the derivative framework of Table 1, Andy could only be identified as an outlier regarding his GC use, without distinguishing between the different GC-based schemes at a finer grain size. The theory of instrumental genesis (Artigue 2002; Drijvers et al. 2013; Guin and Trouche 1998) was helpful in identifying six different instrumentation schemes and in describing the interplay between the technical and conceptual elements in relation both to the artefact and the given tasks.

The case of Andy confirms what Trouche and Drijvers (2010) have already pointed out earlier, namely that the use of technology in education can have complex and subtle effects: instead of being a tool that promotes links between representations, the use of the GC can result in a learning process drawing on graphical and numerical representations, a process that seems to develop separately from symbolic representations.

We also want to reflect on the extent to which the study's results are affected by the instruments used. We observed that links between graphical and symbolical representations were weak for Andy. This result may be affected by the fact that most tasks used in this research did not encourage the use of differentiation rules. However, if in Andy's schemes symbolic differentiation rules were strongly linked to 
velocity, steepness or increase, we could have expected Andy to mention the option of using derivatives. However, this only happened towards the final stage of his secondary school career and, again, he used the derivative as a GC option. This contrasted with his peers who increasingly preferred to use derivatives combined with the use of a tangent for solving the very same tasks (see Roorda et al. 2015). Compared with them, Andy was singular in his intensive use of the GC and with his avoidance of symbolic manipulation.

The generalizability of the results of a case study is an important issue (Lincoln and Guba 2000; Stake 2000; Yin 2014). Lincoln and Guba (2000) argue that, on the one hand, case studies contain factors that are highly specific for the studied context, which cannot be generalized. On the other hand, they suggest that case study results are working hypotheses, which are transferable to some extent. The degree of transferability is a direct function of the similarity between contexts, and working hypotheses may be applicable in other contexts.

In the case of Andy, the teacher mentioned GC options only incidentally. Thus, it was not an exceptional environment in which the GC was excessively promoted. The minimal uptake of GC options by Andy's peers testifies to this. The case of Andy shows that the development of instrumentation schemes in relation to the choices of the teacher is a subtle process with outcomes that are sometimes unexpected. This article presents some evidence that students sometimes rely more on graphical and numerical output of the calculator than on symbolic calculations.

We suppose that such a preference for graphical and numerical representations may occur for several options of the GC, such as finding the point of intersection, calculating extremes and finding an area with an integral. More generally, technology that is used while a student is learning a concept can become an integral part of a student's conceptual knowledge and can strongly influence or even replace mathematical knowledge that is seen as important from the teacher's viewpoint.

One might wonder if it is a problem that Andy did not relate symbolic differentiation rules to GC options. An advantage of Andy's approach is his early uptake of graphical and numerical techniques. While his peers in grade 10 could not solve the tasks on instantaneous rate of change, Andy solved these by approximation by means of a unit interval. This yielded satisfactory answers (in his eyes, at least). A disadvantage of his fruitful approach was that he had few reasons to supplement his schemes with symbolic differentiation rules. We surmise that if Andy succeeds in linking symbolic differentiation techniques to his plot-trace scheme and his calc- $\mathrm{d} y / \mathrm{d} x$ scheme, he will obtain an excellent conceptual understanding of the concept of derivative at layer 3 across all representational aspects (see Table 1).

We assume that there are more students with learning processes similar to Andy. The purpose of this article is not to argue that the GC should not be used in mathematics education, but rather to emphasize that some students strongly rely on graphical and numerical outcomes, resulting in a weak relationship with symbolic representations. These students will benefit from an approach where they are encouraged to discuss relations between symbolic and graphical/numerical representations. Therefore, the case described in this article has a practical relevance for mathematics teachers, because insights into the effects of a GC on mathematical thinking and learning will assist teachers in adapting their teaching to opportunities for and barriers to students' learning processes. 
Open Access This article is distributed under the terms of the Creative Commons Attribution 4.0 International License (http://creativecommons.org/licenses/by/4.0/), which permits unrestricted use, distribution, and reproduction in any medium, provided you give appropriate credit to the original author(s) and the source, provide a link to the Creative Commons license, and indicate if changes were made.

\section{References}

An, H., Alon, S., \& Fuentes, D. (2014). Tablets in K-12 education: Integrated experiences and implications. Hershey: IGI-Global.

Artigue, M. (2002). Learning mathematics in a CAS environment: the genesis of a reflection about instrumentation and the dialectics between technical and conceptual work. International Journal of Computers for Mathematical Learning, 7(3), 245-274.

Berry, J., \& Graham, T. (2005). On high-school students' use of graphic calculators in mathematics. ZDM The International Journal on Mathematics Education, 37(3), 140-148.

Burrill, G., Allison, J., Breaux, G., Kastberg, S., Leatham, K., \& Sanchez, W. (Eds.). (2002). Handheld graphing technology in secondary mathematics: Research findings and implications for classroom practice. Dallas: Texas Instruments.

Cheung, A., \& Slavin, R. (2013). The effectiveness of educational technology applications for enhancing mathematics achievement in K-12 classrooms: a meta-analysis. Educational Research Review, 9, 88-113.

Delos Santos, A. (2006). An investigation of students' understanding and representation of derivative in a graphic calculator-mediated teaching and learning environment. Unpublished Ph.D. Dissertation. Auckland, NZ: The University of Auckland.

Doerr, H., \& Zangor, R. (2000). Creating meaning for and with the graphing calculator. Educational Studies in Mathematics, 41(2), 143-163.

Drijvers, P., \& Barzel, B. (2012). Equations with technology: different tools, different views. Mathematics Teaching, 228, 14-19.

Drijvers, P., \& Doorman, M. (1996). The graphics calculator in mathematics education. The Journal of Mathematical Behavior, 15(4), 425-440.

Drijvers, P., Godino, J., Font, V., \& Trouche, L. (2013). One episode, two lenses. Educational Studies in Mathematics, 82(1), 23-49.

Dunn, P., Richardson, A., Oprescu, F., \& McDonald, C. (2013). Mobile-phone-based classroom response systems: students' perceptions of engagement and learning in a large undergraduate course. International Journal of Mathematical Education in Science and Technology, 44(8), 1160-1174.

Ellington, A. (2003). A meta-analysis of the effects of calculators on students' achievement and attitude levels in precollege mathematics classes. Journal for Research in Mathematics Education, 34(5), 433-463.

Goldin, G. (2000). A scientific perspective on structured task-based interviews in mathematics education research. In A. Kelly \& R. Lesh (Eds.), Handbook of research design in mathematics and science education (pp. 517-545). Mahwah: Lawrence Erlbaum.

Guin, D., \& Trouche, L. (1998). The complex process of converting tools into mathematical instruments: the case of calculators. International Journal of Computers for Mathematical Learning, 3(3), 195-227.

Hähkiöniemi, M. (2006). Associative and reflective connections between the limit of the difference quotient and limiting process. The Journal of Mathematical Behavior, 25(2), 170-184.

Heid, K. (1997). The technological revolution and the reform of school mathematics. American Journal of Education, 106(1), 5-61.

Kendal, M., \& Stacey, K. (2003). Tracing learning of three representations with the differentiation competency framework. Mathematics Education Research Journal, 15(1), 22-41.

Koichu, B., \& Harel, G. (2007). Triadic interaction in clinical task-based interviews with mathematics teachers. Educational Studies in Mathematics, 65(3), 349-365.

Leng, N. (2011). Using an advanced graphing calculator in the teaching and learning of calculus. International Journal of Mathematical Education in Science and Technology, 42(7), 925-938.

Lincoln, Y., \& Guba, E. (2000). The only generalisation is: There is no generalisation. In R. Gomm, M. Hammersley, \& P. Foster (Eds.), Case study method: Key issues, key texts (pp. 27-44). London: Sage Publications.

McCulloch, A. (2011). Affect and graphing calculator use. The Journal of Mathematical Behavior, 30(2), $166-179$. 
Middelink, J. W., Engelhard, F. J., Brunt, J. G., Hillege, A. G. M., De Jong, R. W., Moors, J. H., \& Ottink, H. A. M. (1998). Systematische natuurkunde N1 VWO 1. Baarn: NijghVersluys.

Orton, A. (1983). Students' understanding of differentiation. Educational Studies in Mathematics, $14(3), 235-250$.

Park, J. (2013). Is the derivative a function? If so, how do students talk about it? International Journal of Mathematical Education in Science and Technology, 44(5), 624-640.

Roorda, G. (2012). Ontwikkeling in verandering: Ontwikkeling van wiskundige bekwaamheid van leerlingen met betrekking tot het concept afgeleide. (Development of 'change': The development of students' mathematical proficiency with respect to the concept of derivative.) Unpublished Ph.D. dissertation. Groningen, NL: Rijksuniversiteit Groningen.

Roorda, G., Vos, P., \& Goedhart, M. (2007). The concept of derivative in modelling and applications. In C. Haines, P. Galbraith, W. Blum, \& S. Khan (Eds.), Mathematical modelling (Proceedings of ICTMA 12): Education, engineering and economics (pp. 288-293). Chichester: Horwood Publishing.

Roorda, G., Vos, P., \& Goedhart, M. (2015). An actor-oriented transfer perspective on high school students' development of the use of procedures to solve problems on rate of change. International Journal of Science and Mathematics Education, 13(4), 863-889.

Stake, R. (2000). The case study method in social inquiry. In R. Gomm, M. Hammersley, \& P. Foster (Eds.), Case study method: Key issues, key texts (pp. 20-26). London: Sage Publications.

Thurston, W. (1995). On proof and progress in mathematics. For the Learning of Mathematics, 15(1), 29-37.

Trouche, L. (2004). Managing complexity of human/machine interactions in computerized learning environments: guiding students' command process through instrumental orchestrations. International Journal of Computers for Mathematical Learning, 9(3), 281-307.

Trouche, L., \& Drijvers, P. (2010). Handheld technology for mathematics education: flashback into the future. ZDM - The International Journal of Mathematics Education, 42(7), 667-681.

Vergnaud, G. (2009). The theory of conceptual fields. Human Development, 52(2), 83-94.

Yin, R. (2014). Case study research: Design and methods (5th ed.). Thousand Oaks: Sage Publications.

Zandieh, M. (1997). The evolution of student understanding of the concept of derivative. Unpublished Ph.D. dissertation. Corvallis: Oregon State University.

Zandieh, M. (2000). A theoretical framework for analyzing student understanding of the concept of derivative. In E. Dubinsky, A. Schoenfeld, \& J. Kaput (Eds.), Research in collegiate mathematics education IV (pp. 103-127). Providence: American Mathematical Society. 